\title{
ILLUSION OR DECEPTION: THE USE OF "PROPS" AND "MOCK-UPS" IN TELEVISION ADVERTISING
}

AN ice-cream manufacturer, hoping to advertise his goods on television, can hire the most creative agency and use the most advanced technical equipment, but still be unable to show the world his product. A few minutes under hot studio lights and he is extolling the virtues of vanilla consumé, hardly a gourmet's delight. He has lost what is sometimes called the "Unique Selling Proposition," a product's most salient and saleable quality. ${ }^{1}$ But the plight of the ice-cream maker is not unique, for the technical difficulties confronting him are not peculiar to his product. Blue shirts, for example, look white on television; butter looks like white oleomargarine. To compensate, television advertisers successfully have used props and mock-ups, ${ }^{2}$ designed to appear on television as their products do in real life. ${ }^{3}$ The death-knell of this practice, however, may recently have been tolled by the Federal Trade Commission in Colgate Palmolive Co., the "sandpaper" case.4

Involved was the legality of a television commercial in which "Palmolive Rapid Shave" was applied to a piece of plexiglass covered with sand, which an announcer called "sandpaper." Use of this mock-up was necessitated by the inherent difficulties of television photography-real sandpaper is indistinguishable from smooth colored paper.5 An actor shaved the mock-up clean in a stroke, claiming to prove that "Rapid Shave" is so highly moist that it can shave the heaviest beard in seconds. The Commission held the commercial deceptive, finding that "Rapid Shave" in fact could not shave true sandpaper even after an hour of soaking. But the Commission went much further. It stated that the use of the mock-up would constitute an illegal deception even if the shaving cream could actually shave real sandpaper as fast as it shaved the mock-up and in every other particular was exactly as depicted in the commercial. 6 Thus the FTC, albeit in dictum, announced its intention to prohibit absolutely the use of any prop or mock-up in a commercial message on television except as background material.

The source of the FTC's general powers to regulate advertising is section 5

1. See Mayer, Madison Avenue, U.S.A. 49-53 (1958).

2. In advertising a "prop" or "mock-up" is an object or device used in a television commercial for a particular purpose relevant to the commercial message. Frequently it is something made solely for use in the commercial and often it is made to simulate a real object. Any minor differences between a "prop" and "mock-up" are irrelevant for purposes here.

3. See Printer's Ink, Oct. 30, 1959, p. 14.

4. Colgate-Palmolive Co., 3 TRADE REG. REP. If 15,643 (1961).

5. Brief for Respondent, p. 3, Colgate-Palmolive Co., Inc., stipra note 4.

6. The heart of these commercials was the visual "sandpaper test"-a test that was, in reality, not taking place. This would be deceptive and unfair advertising even if "Rapid Shave was as effective in shaving sandpaper as respondents represented."

Colgate-Palmolive Co., 3 Trade REg. REp. II 15,643, at 20,480 (1961) (emphasis added). 
of the Federal Trade Commission Act, ${ }^{7}$ which formerly authorized the Commission to prohibit "unfair methods of competition in commerce." This original grant of power restricted the Commission to acting upon false advertising only if it was likely to injure competitors of the advertiser. ${ }^{8}$ But in 1938 Congress passed the Wheeler-Lea Amendment, which extended the Commission's authority over "unfair or deceptive acts or practices in commerce." The extension was motivated by a desire to afford consumers greater protection from false advertising. ${ }^{10}$ Although the indefinite language of the provision itself suggests a broader scope, discussion of the amendment in Congress indicates that the acts intended to be proscribed were those which cause or threaten to cause injuries to consumers:

By the proposed amendment to section 5, the Commission can prevent such acts or practices which injuriously affect the general public as well as those which are unfair to competitors. In other words, this amendment makes the consumer, who may be. injured by an unfair trade practice of equal concern, before the law, with the merchant or manufacturer injured by the methods of a dishonest competitor. ${ }^{11}$

The amendment thus enabled the Commission to prohibit advertisements merely by showing an injury to consumers, without first having to establish adverse effects upon competition in general. Moreover, since the emphasis was upon protecting consumers from injuries, the central concern was with the effects of advertisements rather than particular devices or methods employed by advertisers. The question posed by the "sandpaper" case would thus seem to be whether the use of props or mock-ups in television commercials injure or create a risk of injury to consumers or competitors. Standards for determining such an injury, unfortunately, are neither to be found in the statute nor in the legislative history, since Congress never made clear what it meant by "injury."12

7. 38 Stat. 719 (1914), as amended, 15 U.S.C. $\$ 45$ (1958).

8. Raladam Co. v. FTC, 42 F.2d 430 (6th Cir. 1930), aff'd on other grounds, 283 U.S. 643 (1931).

9. Section 5(a), 52 Stat. 111 (1938), 15 U.S.C. $\$ 45$ (a) (1) (1958).

10. See Handler, The Control of False Advertising Under the Whecler-Lea Act, 6 Law \& Contemp. Prob. 91, 96 (1939).

11. H.R. Rep. No. 1613, 75th Cong., 1st Sess. 3 (1937). See also, 83 Conc. Rec. $391-92$ (1938) (remarks of Congressman Lea):

The principal feature of the Federal Trade Commission Act is in section $5 . \ldots$ One thing we propose in the pending bill ... is that it is sufficient to establish the unfair practice without showing injury to a competitor... Indeed, the principle of the act is carried further to protect the consumer as well as the competitor . . . and afford a protection to the consumers of the country that they have not heretofore enjoyed.

See also Report to the President by the Atrorney General on Deceptive Practices IN Broadcasting Medta 37 (1959).

12. The law in this area currently is in its infancy, although it lately has begun to develop with a few FTC complaints and cease and desist orders:

One area of advertising ... is of particular interest to those who advertise on television. This is the practice of attempting to prove some superiority or desirable quality of a product by means of a demonstration or test pictured on the telcvision 
In deciding whether a particular practice constitutes an injury, several factors would seem relevant. The need to protect consumers from the harms of false advertising is, of course, clear and generally recognized. ${ }^{13}$ This goal necessitates a careful examination of the kind of injury, if any, attributable to the use of props or mock-ups. But aside from injury, the benefits and detriments of any particular form of advertising would not seem to be the concern of the FTC, ${ }^{14}$ for the Commission is limited to a policing function, designed

screen .... No authoritative precedents were established [in the early FTC actions], because they were not contested but were settled with the consent of the advertisers. However, they indicate the types of practices which the Commission believes to be unfair in connection with demonstrations and tests of products on television commercials.

2 TRADE ReG. REP. I 7805, at 12,663-64 (1961). But the advertising businessman is suffering the growing pains, because there have been no guidelines or comprehensive rules formulated by the courts as to how far an advertiser may go in the use of props or mock-ups in television commercials. See, e.g., Needed Now: FTC Clarification on TV "Deccption," an editorial, Printer's Ink, Jan. 12, 1962, pp. 12-13. See also Printer's Ink, Feb. 2, 1962, p. 57. True, if his commercial should be held illegal, he is usually subject only to a cease and desist order. Section 5, 38 Stat. 719 (1914), as amended, 15 U.S.C. $\S 45$ (1958). But when a television commercial costs thousands of dollars to produce, there is a very real injury sustained when the advertiser is required to abandon it without even recapturing his investment. Cease and desist orders also occasionally are directed to the advertising agency as well as the advertiser [e.g., Colgate-Palmolive Co., 3 TRADE REG. REP. $\$ 15,643$ (1961) ], and are couched in rather broad terms. The statute, in fact, authorizes the FTC to order advertisers "to cease and desist from using such method ... or practice" it finds illegal [§ 5(b), 38 Stat. 719 (1914), as amended, 15 U.S.C. § 45(b) (1958)], and orders frequently extend to "other similar products" beyond that involved in the litigation. See, e.g., American Tack Co. v. FTC, 211 F.2d 239 (2d Cir. 1954). Thus, an agcncy employing another kind of prop or mock-up for another client which the Commission might deem a "similar practice" could be found guilty of violating the Commission's order and fined as much as $\$ 5,000$ for each day he used the illegal commercial, $\S 5(1), 38$ Stat. 719 (1914), as amended, 15 U.S.C. § 45(1) (1958). Recently, for example, the FTC filed a civil penalty suit asking a total judgment of $\$ 185,000$ for 37 alleged violations of a 1939 cense and desist order. FTC, News and Summary, Jan. 19, 1962, p. 4. Finally, the food, drug, and cosmetic sections of the F.T.C.A. make it a misdemeanor to disseminate "false" advertisements, punishable by a fine up to $\$ 10,000, \S \S 12,14,15,52$ Stat. 114 (1938), 15 U.S.C. $\S \S 52,54,55$ (1938).

13. See, e.g., Handler, supra note 10.

14. The arguments in favor of advertising have been recited in many places. Sec, e.g., Brown, Advertising and the Public Interest: Legal Protection of Trade Symbols, 57 Yale L.J. 1165 (1948) ; Hotchkiss, An Economic Defense of Adverlising, 15 A3r. Econ. REv. Supr. 14 (1925). Equally omnipresent has been the recitation of arguments the other way. E.g., Brown, supra; and Bishop, The Econoartcs of Advertrsing Chap. 8 (1946). It is without regret that this raging controversy is side-stepped here. It is, however, generally accepted that some form of communication about the existence of competing products and their relative merits-advertising-is necessary in an economy where distribution is determined by consumer preferences, notwithstanding these sentiments of the late Judge Learned Hand:

[T] he art of publicity is a black art; but it has come to stay, every year adds to its potency, and to the finality of its judgments. The hand that rules the press, the radio, the screen and the far-spread magazine, rules the country; whether we like it or not, we must learn to accept it.

Proceedings in Memory of Mr. Justice Brandeis, 317 U.S. IX, XV (1942). 
to protect certain groups from deceptive practices in advertising and, at the same time, to allow advertisers maximum freedom in their choice of advertising content and media. These objectives, however, cannot be achieved unless some standard for prohibiting "deceptive" advertising is articulated. As defined and applied in the non-television false advertising cases decided under section 5 (a), the criterion suggested by the legislative history-injurious effects upon consumers and competitors-not only affords ample protection to the consuming public and allows maximum freedom to advertisers, but also takes account of the technical difficulties presented by television as an advertising medium.

An examination of these cases reveals several general types of injuries that have come to be proscribed by the act. First, advertising claims which conceal latent dangers to consumers or mislead consumers into thinking a potentially dangerous product ${ }^{15}$ is entirely safe have been banned from the earliest days. In Gelb v. FTC, ${ }^{16}$ for example, it was held that the makers of "Instant Clairol," a hair dye, must disclose in their advertisements that the product could inflict skin irritation upon persons allergic to its ingredients and blindness if used to color eyelashes or eyebrows.

Second, advertisements consistently have been held illegal if they contain a false claim which might induce a consumer to purchase a product under expectations that he will acquire something better than the product being offered. The "injury" to the consumer lies in his not getting what he bargained for. The clearest example of such advertisements are those ascribing a quality, ${ }_{1}^{17}$ ingredient, ${ }^{18}$ or effectiveness ${ }^{10}$ to a product which in fact it does not possess. ${ }^{20}$

15. The term "product" is used throughout this Comment in the broad sense to include both goods and services offered consumers through advertisements.

16. 144 F.2d 580 (2d Cir. 1944).

17. FTC v. Algoma Lumber Co., 291 U.S. 67 (1934) (holding illegal advertisements using the words "California white pine" to describe a less desirable kind of pinewood called "pinus ponderosa"). But see Ostermoor \& Co. v. FTC, 16 F.2d 962 (2d Cir. 1927). 'There petitioner had featured in magazine advertisements pictures of his mattresses cut open with the stuffing rising above the mattress some 35 inches. The purpose was to demonstrate how much stuffing the mattresses contained, but in fact there was only enough to cause a 3 to 6 inch rise. The court vacated the FTC's cease and desist order, holding that petitioner's practices constituted mere "puffing," which could not "be deemed to be either a misrepre. sentation or an unfair method of competition:" (Id. at 963.) This decision has received very little following, and it is highly doubtful whether trends following the passage of the Wheeler-Lea Amendment have not in effect overruled it.

18. Jacob Siegel Co. v. FTC, 327 U.S. 608 (1946) (reversing and remanding on other grounds where the Circuit Court had affirmed a cease and desist order against advertise* ments for fur coats, featuring the name "Alpacuna" when the product contained no vicuna fur).

19. Best known of these cases is Carter Prods., Inc. v. FTC, 268 F.2d 461 (9th Cir.), cert. denied, 361 U.S. 884 (1959), enforcing an FTC order that Carter eliminate the word "Liver" from the trade name of its "Little Liver Pills," when it was shown that the product had no curative or active effects upon the liver. Probably the most extreme case involved false advertising claims that a mineral water could cure some 52 infirmities, running tho gamut from poison ivy to sterility. Capon Water Co. v. FTC, 107 F.2d 516 (3d Cir، 1939).

20. Also included in this category are false claims about where a product was made. Houbigant, Inc. v. FTC, 139 F.2d 1019 (2d Cir.), cert. denied, 323 U.S. 763 (1944) 
Somewhat similar is testimonial advertising, which induces a consumer to purchase a product because of an opinion by someone he respects. If the testimonial is untrue, the consumer does not get what he expects in terms of the popularity or prestige of the product.21

Section 5(a) has also been applied against advertisements which tend to create a false impression about the advertised product which might motivate the consumer to make a particular purchase, regardless of whether he ultimately acquires everything he fully expected. The leading case, Kcrran v. FTC, involved an advertiser of "refined oil" who neglected to inform the public that his oil actually was second-hand, having been re-refined from used oil. The Commission held that the advertiser could be compelled to disclose this fact, even though it was conceded that both "new" and "used" oil properly re-refined were equally effective lubricants. The dissenting opinion, arguing against disclosure, based its contention on the proposition that the consumer, who desires merely "good" oil, is not prejudiced by any erroneous impression an advertisement might give him so long as he acquires the "good" oil he wanted. That is, if what the consumer acquires squares with his expectations before purchase,

("French" perfume made in the U.S.). Cf. Edward P. Paul \& Co. v. FTC, 169 F.2d 294 (D.C. Cir. 1948) ("DuBarry" on labels held deceptive when the porcelain originated in Japan). Similarly illegal are claims misrepresenting the manufacturing process, less tangible properties than the others, perhaps, but nonetheless commodities in exchange for which consumers are willing to pay money. FTC v. Royal Afilling Co., 288 U.S. 212 (1933) (prohibiting advertisers from misleading consumers into thinking their operation included grinding flour when their activities were limited to blending various hinds of flour). Congress has specifically labeled "misleading" the advertising of oleomargarine in a way which suggests it is a dairy product, $\S 15(a)(2), 52$ Stat. 116 (1938), as amended, 15 U.S.C. $\S 55$ (a) (2) (1958). Use of the word "churned" in describing the process of malking olcomargarine was held to have violated this statute in E. F. Drew \& Co. v. FTC, 235 F.2d 735, 740 (2d Cir. 1956). Finally, there are advertisements which falsely represent the size or facilities of the manufacturer. Consumers often purchase from large, well-established firms dealing in large volume turnover under the frequently correct assumption that they are buying convenient repair or replacement services. They do not get all they bargained for when the manufacturer turns out to have a small, faltering business which cannot perform these future services. See, e.g., Consolidated Book Publishers, Inc. v. FTC, 53 F.2d 942 (7th Cir. 1931), cert. denied, 286 U.S. 553 (1932), involving a publisher of encyclopedias who sold his wares by misrepresenting that he maintained an extensive research bureau which would answer all inquiries from subscribers. In fact, his "burcau" consisted of two men in a one-desk office. See also, L. \& C. Mayers Co. v. FTC, 97 F.2d 365 (2d Cir. 1938) (prohibiting a jeweler from advertising himself as a "wholesaler" when he sold to individual consumers at prices above the normal wholesale level).

21. Cases have held that when a testimonial has been purchased or solicited, advertisements which imply otherwise are illegal. E.g., FTC v. Inecto, Inc., 1932-39 Trade Cas. If 55,068 (2d Cir. 1935). This policy has been incorporated by the FTC in several sets of Trade Practice Conference Rules. See Note, 17 Gzo. Wash. L. Rev. 340, 349 \&.41 (1949). False insinuations that a product has been endorsed by celebrities [Howe v. FTC, 148 F.2d 561 (9th Cir. 1945)], professions [Mforetrench Corp. v. FTC, 127 F.2d 792, 795 (2d Cir. 1942)], or fictitious individuals [Doeskin Products, Inc., 48 F.T.C. 1331 (1952)] also have been enjoined.

22. 265 F.2d 246 (10th Cir. 1959). 
he receives what he bargained for and there is no "public interest" in prohibiting advertisements that communicated to him some kind of falsehood. The majority, however, reasoned that the public "is entitled to know the facts ... and ... make its own choice with respect to purchasing ... even though the choice is predicated at least in part upon ill-founded sentiment, belief or caprice."23 The injury, then, lies in the deprivation of a truthful factual basis upon which the consumer may rely in deciding to purchase the advertised product. ${ }^{24}$ Kerran also serves to show that a deception can consist not only in an express statement that is untrue, but in a silence that leads a reasonable man to infer a false notion. 25

The fourth type of advertisements brought under Section 5 (a) involves injuries to competitors. Advertisements which mislead a buyer into acquiring something other than he expects simultaneously divert potential sales from competitors who do not indulge in similar advertising practices. Competition, of course, is supposed to stimulate improvements in consumer goods by favoring sellers of superior goods over others in the same price-range. The false advertiser, however, attains a better position in the competitive market not on the strength of a superiority inherent in his goods, but upon a fiction communicated through his advertisements. ${ }^{26}$ Finally, Section 5 (a) has been held to prohibit false advertising which ascribes to competitive products inferiorities they do not in fact possess ${ }^{27}$ or which falsely disparages the competitors themselves. ${ }^{28}$

These cases make clear, then, that some actual or potential injury to consumers or competitors has been the determinative factor in finding deception in an advertising practice, although the particular injury has taken various forms. In deciding the question of proper use of props and mock-ups in television commercials, however, the FTC has failed to carry forth this earlier focus upon effects. Instead, it has tended to categorize the cases with an undue emphasis upon the subject matter or devices employed in the commercial, without fully examining the effect of the advertisement on consumers and competitors. ${ }^{29}$ Yet there is no apparent reason for approaching television problems any differently from others, for the injuries are identical whether the advertising claim is communicated by the written word or through a combination of

23. Id. at 248.

24. Accord, Royal Oil Corp. v. FTC, 262 F.2d 741 (4th Cir. 1959).

25. This broader meaning of "falsity" is adhered to throughout this Comment. A "false" claim refers to both an express falsity or one resulting from silence in an advertisement.

26. E.g., FTC v. Algoma Lumber Co., supra note 19.

27. E.g., Perma-Maid Co. v. FTC, 121 F.2d 282 (6th Cir. 1941) (manufacturers of steel cooking ware enjoined from claiming that food prepared in aluminum utensils causes ulcers and cancer). Accord, Steelco Stainless Steel, Inc. v. FTC, 187 F.2d 693 (7th Cir. 1951).

28. A large retail concern, for example, was prohibited from publishing advertisements containing statements implying that its competitors were unfair and dishonest. Sears, Roebuck \& Co. v. FTC, 258 Fed. 307 (7th Cir. 1919).

29. Cases referred to here are those discussed in note 34 infra. 
oral words and moving images. Thus, for example, an advertiser who uses a prop or mock-up to "demonstrate" or "prove" that his product possesses certain characteristics which it does not possess stands in the same position as one who makes such misrepresentations by use of the written word. In either case, the consumer is misled into buying something for which he did not bargain.

Although it is perhaps not feasible to list all conceivable injuries that could be produced by use of props and mock-ups in television commercials, it is necessary to identify a range of injuries from which the consumer may be protected in order that a fair standard of conduct for the advertisers as well as a workable guide for enforcement of the statute may be formulated. At one extreme is the actual physical injury to the consumer caused by a concealment of dangers inherent in the product; ${ }^{30}$ at the other is injury to the consumer's self-reliance resulting from his loss of an adequate factual basis for the purchase decision. ${ }^{31}$ In between fall many situations in which the injury to the consumer is frustration of justifiable expectations. ${ }^{32}$ The common denominator of all injuries within this spectrum is that they result from the consumer acquiring a product which in some way is different from what was advertised. Prior to its decision in the "sandpaper" case, ${ }^{33}$ the FTC banned only those television commercials that involved the use of props or mock-ups that threatened to produce injuries falling somewhere within this spectrum. ${ }^{34}$ But the dictum in the "sandpaper"

30. E.g., Gelb v. FTC, 144 F.2d 580 (2d Cir. 1944). See note 16 supra and accompanying text.

31. E.g., Kerran v. FTC, 265 F.2d 246 (10th Cir. 1959). See notes $22-24$ supra and accompanying text.

32. This expectation may relate either to the product's character (see notes 17-20 supra and accompanying text) or to factors of a more collateral nature (as in the testimonial cases, note 21 supra and accompanying text).

33. Colgate-Palmolive Co., 3 TrADE REg. REP. If 15,643, at 20,480 (1961).

34. The opinions in these several cases frequently emphasize the type of falsity represented or the manner in which it is conveyed rather than focusing upon the injurious effects created. Nonetheless a reinterpretation of the decisions reveals their similarities to the nontelevision cases discussed in notes 16-28 supra and accompanying text.

1. Use of props or mock-utps to communicate non-existent facts about the product or the manufacturer. In 1958 the Commission entered a consent decree against the manufacturer of a liquid detergent, "Lestoil," alleging that television commercials had tended to represent the product as possessing non-combustible qualities when in fact it possessed a "dangerously low flash point" The commercials featured scenes in which a bottle of "Lestoil" was placed near a burning candle and atop a radiator and stove. (The falsity, obviously; threatened to lead to physical harm as discussed in text accompanying note 16 supro.) Adell Chem. Co., 54 F.T.C. 1801 (1958), complaint, Trade Reg. Rep., 1957-58 F.T.C. Complaints and Orders $\mathbb{I} 26,987$ (hereinafter cited as $C$ and $O$ by year). (The record in a consent decree consists wholly of the decree itself and the complaint. All cases reaching consent decrees will be cited to both the decree and the complaint, since the facts as alleged by the Commission are available only in the latter.)

At least two cases involved the use of a prop or mock-up to ascribe a quality to the advertised product which it did not possess. Consumers purchasing in reliance would not get what they expected. This "injury" is discussed in notes 17-28 supra and accompanying text. In 1959 the manufacturers of "Natural Wave," a hair-curling lotion, developed television commercials in which they used as a prop an ordinary drinking straw soaktied in the 
case, suggesting that use of props or mock-ups as an integral part of a television commercial message causes injury even if there is communicated to the consumer no false impression as to the nature or quality of the advertised product, would extend this spectrum.

lotion to demonstrate that the product penetrates hair, changing its structure and creating a "natural" curl. A consent decree was issued on the allegation that "Natural Wave" possessed no abilities to change the basic structure of human hair nor change naturally straight hair to naturally curly. Max Factor \& Co., 55 F.T.C. 1328 (1959), Complaint, 1957-58 $\mathrm{C}$ and $\mathrm{O}$ \{ 27,510. An initial contested cease and desist order recently was rendered against the "invisible shield" commercial. The Hearing Examiner ruled that by using a picce of transparent glass to shield an announcer from flying objects, the commercial tended to ascribe to the toothpaste it was advertising properties it did not possess (formation of an invisible protective shield around teeth). Colgate-Palmolive Co., 1960-61 C and O \28,947.

The Commission also banned a television commercial in which props were used to misrepresent the mature and facilities of the advertiser's enterprise (see note 20 supra). Witkower Press, Inc., 1959-60 C and O $\{28,371$. There the FTC enjoined the use of television commercials in which the author of "Arthritis and Common Sense" appeared to advertiso a book claimed to contain details of a cure for arthritis. The film studio in which his commercials were made had been set up to resemble a laboratory by the use of such props as test tubes and white jackets. The commercial featured a demonstration of "the fastest possible way to relieve arthritis," which consisted of mixing cod liver oil with orange juicc. The entire film created an erroneous impression that the advertiser maintained a complete medical laboratory and that his "cure" involved elaborate scientific processes. The buyer who relied on these commercials did not get a scientifically prepared medicine; he got a concoction of cod liver oil, fruit juice and a book of highly questionable "theorics."

There has been, finally, one instance in which the Commission registercd its opinion that television props were being used to violate standards of testimonial advertising (note 21 supra and accompanying text). American Chicle Co., 54 F.T.C. 1625 (1958). Complaint, 1957-58 $\mathrm{C}$ and $O \Uparrow 26,501$. This case resulted in a consent decree banning a commercial for "Rolaids," an indigestion remedy, in which an announcer appeared in a white coat, addressed as "doctor." The complaint alleged that these practices "convey to TV viewcrs that Rolaids are endorsed by the medical profession" when they were not, and therefore that they "have the capacity to deceive a substantial portion of the purchasing public and are unfair and deceptive practices in violation of the FTC Act." The effect of such a practice, of course, was to mislead consumers into thinking they were acquiring a product of stich high quality as to merit a recommendation by the medical profession. When they acguircd a product that did not carry such credentials they did not get all they bargained for.

2. Use of props or mock-ups to distort results of comparative tests.

The use of props or mock-ups to distort the results of "tests" to the advertiser's favor can be viewed as a violation of the Kerran standards (notes 22-24 supra and accompanying text). Even if the advertiser's product actually is superior, the false test relating to the product threatens to be the moving force in persuading a consumer to change his position, If the advertiser's product actually is inferior, there is created a false disparagement of the competitive product (see note 27 supra and accompanying text). This principle justifies three recent FTC orders banning television commercials using a simulative device to prearrange a comparison test. The first was directed at the Mennen "underwater test," showing a swimmer beneath the surface of water applying, first, a competitive acrosol shaving cream to his cupped hand, then the advertiser's "Sof' Stroke." The former floated quickly away, the latter remained in the palm of the hand, giving the impression that the competitive brand lacked the consistency of the advertiser's. The trouble was that the swimmer cupped his hand at a sharper angle when applying the competitive cream, thus facilitating the result. The Mennen Co., 3 Trade REg. REp. $\lceil$ 15,133 (1961). The sccond, 
Such an extension would severely limit the effectiveness of television advertising. It is generally recognized that technical limitations of the television medium require use of props or mock-ups in order to communicate in any manner the image of certain objects. It is obviously impossible to transplant most natural and many artificial objects into a small television studio. Limitations of space require the use of artificial props designed to resemble moun-

a demonstration of comparative efficiency of aluminum wrap in preserving the freshness of hams, also resulted in a consent decree. Aluminum Co. of Amer., Dht. 7735, 3 TrADE REG. REP. If 25,448 (1961). There the commercial claimed two hams had been wrapped simultaneously, one with a competitive foil, the other with respondent's. When each was unwrapped during the commercial, only the ham in respondent's wrap appeared fresh. The competitor's wrap appeared to have been unable to preserve the meat and the wrap scemed to have become damaged and torn. Actually the advertiser had originally sclected a dricd ham for his competitor's wrap, and had deliberately subjected his competitor's product to abuse before the commercial began. Third was a television commercial for "Rise Shaving Cream." In handing down a final cease and desist order, the FTC found that respondent had used a "phony substance resembling shaving cream" in a commercial which stated that "Rise," when applied to the face, remained moist long after competitive brands dried out. The commercial clearly showed such a result, but the Commission found that only the "Rise" cream was authentic. "Brand X" really was a white mock-up, 90\% vater and 10\% foaming agent, made to simulate shaving cream, but designed to disappear rapidly. Soap and fatty acids, which usually are used in shaving cream to prevent breakdown, werc omitted from the mock-up. Carter Products, Inc., 3 Trade Reg. Rer. I 15,859 (1962).

3. Use of props or mock-ups in tests or demonstrations that do not prove twhat is purported.

This approach also violates the Kerran standards (notes $22-24$ supra and accompanying text). An authentic test showing a product's superiority may be the final bit of persuasive evidence that drives the consumer to the market. If the test proves nothing, the consumer has changed his position relying on a falsity about the product's capabilities, and thus deprived of a truthful factual basis upon which to make his purchase choice, regardless of whether the product actually possesses the superiority purportedly proved.

There is a leading pre-television case directly relevant to this topic, Bristol-Mrycrs Co. v. FTC, 185 F.2d 58 (4th Cir. 1950), which held illegal an advertising claim that "Dentists choose Ipana for personal use 2 to 1 over any other dentifrice." The claim was based upon a 1940 survey conducted by the advertiser in which he mailed questionnaires to 10,000 of the 66,000 dentists in the country. Of the 1983 responses, 621 said they used Ipana most often, 258 named a second brand, 189 a third, $144 \mathrm{a}$ fourth and 128 a fifth. In addition, the dentists were asked to identify which brand they most often recommended to patients. Ipana was listed in 461 answers, a second brand in 195, a third in 125, a fourth in 106, and a fith in 94. From these figures the advertisers concluded that "more dentists said they recommended Ipana for their patients' daily use than the next two dentifrices combined." The trouble was that the number of responses simply did not justify the conclusions announced. The survey did not establish what was purported.

The most authoritative FTC word on this matter appears in a decision dismissing a complaint against the "flaming auto" commercial. Hutchinson Chem. Corp., 55 F.T.C. 1942 (1959). The case was dismissed for lack of evidence that a test shown in the commercial did not prove what was purported, but in the opinion the Commission announced its intention to ban any future commercials containing this kind of deception, and identified the public injury latent in such a practice:

[I]t would have the tendency and capacity to mislead purchasers into believing that they are buying a product which has been demonstrated or proven to have a certain quality or characteristic. The law is well settled that the public is entitled to buy 
tains, houses, lakes, and so forth. ${ }^{35}$ Time limitations ${ }^{36}$ prohibit showing the entire development in a sequence of events; instead, the technique of showing three successive views--"before," "middle" and "after," using three separate objects frozen at those stages of development-frequently is used. Sound problems often necessitate a singer's merely "lipping" a pre-recorded song, to permit on-stage dancing or changing of scenery which would create disruptive noises were the microphones turned on. ${ }^{37}$ The same problems, of course, face television advertisers, and they try to solve them similarly:

Like all visual arts, television relies on certain production techniques intended to compensate for limitations imposed by studio facilities and clectronic distortions. As the public knows, performers wear blue shirts on television because a white shirt creates undesirable highlights and a blue shirt looks white. By the same token, yellow looks grey on television. The same is true of foods in television commercials. Some preparations must be tinted so they will look as white as they do in real life....

In other words, an advertising agency in every medium of advertising relies on special techniques to create reality, not to misrepresent but rather to represent accurately. ${ }^{38}$

The advertiser in the "sandpaper" case attempted to justify the use of a plexiglass mock-up and any possible resultant injury on the ground that the problems of photography necessitated its substitution for real sandpaper. ${ }^{30}$ But in

what it thinks it is buying, in this case, a product which has been subjected to a test which demonstrates that it imparts a finish which is both heat and cold resistant.

Id. at 1947.

More recently, the Commission entered a consent decree against an oleomargarine advertiser, alleging deceptive practices in conducting a test in which "moisture drops" appeared only on oleomargarine and not on butter. The commercial claimed this proved that the margarine tastes better; but the FTC claimed it did not. Standard Brands, Inc., 1960-61 $\mathrm{C}$ and $\mathrm{O}$ II 28,819, complaint, 1959-60 C and $\mathrm{O}$ of 28,491 (1960). A television commercial in which an announcer cut a boxing glove by stroking a competitor's safcty razor across its surface, but did not cut the glove when he repeated the procedure with a "Schick" razor was also the subject of a consent decree. The announcer insinuated that the test proved the advertiser's product would not cut a person's face. The FTC claimed that the surface of a boxing glove was so dissimilar to a person's face that no such thing was proved. Eversharp, Inc., 1960-61 C and O ๆ 29,094 (1960), complaint, 1959-60 C and O I 28,627. Tho Commission also secured a consent decree against a test for Life cigarette's "Millicel Filter," in which liquid was poured into two tubes, one plugged with Life's filter, the other with a competitor's. The liquid soaked through the other filter, but not through Life's. The commercial claimed this test proved that Life's filter absorbs more tars and nicotines from cigarette smoke; the FTC charged the test did not prove what was purported. Brown and Williams Tobacco Corp., 1959-60 C and O \28,631, complaint, id. at $\Uparrow 28,491$ (1960).

35. See generally Bettinger, Television Techntgues 15 (1947), and Eddx, Televiston, THe Eyes OF TOMORROW 211-28 (1945).

36. See generally BETTINGER, op. cit. silpra note 35, at 13-15.

37. See generally $i d$. at 16 .

38. Statement of Ted Bates \& Co., quoted in Printer's Ink, Oct. 30, 1959, p. 14. Simllar$1 y$, radio advertisers traditionally have resorted to such strictly false devices as bacliground music and sound-or-special-effects. See Wolfe, Modern Radro Adverrising 44, 521-22, 569-76 (1949).

39. See Motion by Defendant Ted Bates \& Co., Inc., Brief for Defendant, p. 11, Colgate-Palmolive Co., supra note 33 . 
rejecting "technical difficulties" as a justification for any deception, the Commission stated:

... assuming it to be the fact that there are indeed such limitations in television photography, the Commission can appreciate that these "technical" difficulties could give rise to problems for sponsors and agencies in determining how most effectively to use television in advertising their products. The limitations of the medium may present a challenge to the creative ingenuity and resourcefulness of copywriters; but surely they could not constitute lawful justification for resort to falsehoods and deception of the public. ${ }^{40}$

This zealous desire for the truth seems misplaced. True, the use of a prop or mock-up may be characterized as a falsehood. But it is another thing to say that the use of mock-ups constitutes a deception of the public. Such a view seems more concerned with what occurs in the television studio than with the message projected on the screen. Under this view, an advertiser may not use a prop or mock-up to show the actual qualities of a product or its performance, although it might be lawful for him to exploit the distortions of television projection to make a product or its performance appear superior on the screen, so long as he uses the real object in the studio. Clothes still gray and dingy after being washed in Brand $X$ soap, for example, could then be televised even if they appear whiter and brighter than they really are. And if this also is deemed illegal, the advertiser is in the unenviable position of not being able to use the real object in an advertisement because that would be misleading and not being able to use a prop which appears like the real object on the screen because that too would be misleading. In short, he may not show his product or its performance on television.

The difficulties presented by the FTC's current view are in part attributable to a failure to distinguish between deception to the general public and to the consuming public, and therefore between "injury" to these groups. But the legislative history of Section 5(a), 11 however scant, and the treatment of non-television advertising cases ${ }^{42}$ suggest that a commercial does not constitute a deceptive practice prohibited by Section 5(a) unless the falsity employed by the advertiser causes injuries to the consumer. ${ }^{43}$ The solution to the problem, then,

40. Colgate-Palmolive Co., supra note 33 , at 20,481 .

41. See notes 7-11 supra and accompanying text.

42. See notes 15-29 supra and accompanying text.

43. Except for the injury caused by disparagement of competitors or their products, a protection of consumers will afford full protection to competition under $\S 5(a)$. The statute does not contemplate protecting a competitor from loss of business due to consumer preferences based upon accurate claims concerning the products, for that is the essence of the competition being preserved. Rather, it contemplates an injury in the form of loss of business the competitor might have enjoyed but for the consumer's being attracted to the advertiser's product by the false claim. The competitor is "injured" in the $\$ 5$ meaning whenever the consumer is "injured," since, as is discussed in the text, the consumer's injury is in acquiring a product that is different from what was advertised. That is, the competitor is deprived of sales on factors other than actual differences between his and the advertiser's product. The competitor injury from disparagement is not here considered, for any adver- 
depends upon isolating those injuries peculiar to consumers and not shared by the general public.

The distinguishing characteristic of a consumer is that he has or will acquire a product. Thus, any false claim in an advertisement must relate to this acquired product in order to constitute consumer injury. That is, the false claim must give the consumer a concept of the product different from what he actually acquires, for only such injuries are peculiar to the consumer class alone. As the spectrum of injuries identified earlier is defined in terms of this same relationship between the false claims in advertisements and the nature of the acquired product, ${ }^{44}$ the spectrum necessarily includes those consumer injuries envisioned by Section 5(a). Considerations of fairness to advertisers in their attempt to compensate for the technical limitations of television require such a strict interpretation of Section 5(a). As indicated earlier, some products are ill-suited to television photography, ${ }^{45}$ and to deny the use of props or mock-ups to their manufacturers would be to deny them the use of television, ${ }^{40}$ or at least

tisement that falsely disparages a competitor or his product should be prohibited regardless of whether a consumer is adversely affected. See notes 27-28 supra and accompanying text. Cf. 1 HARPER \& JaAres, Torts $\S 6.1$ (1956). Discussion of this form of injury is beyond the scope of this Comment. See generally Tex Smith, The Harmonica Man, Inc. v. Godfrey, 198 Misc. 1006, 102 N.Y.S.2d 251 (1951), and Advance Music Corp. v. American Tobacco Co., 296 N.Y. 79, 70 N.E.2d 401 (1946).

44. See text accompanying notes 30-32 supra.

45. See note 38 sitpra.

46. The effectiveness of the television commercial is hardly disputed, for it alone appeals to both of man's most receptive senses-hearing and seeing:

Television's communication of ideas has the advantage of oral communication plus the merits of printed communication, with the addition of movement, to give television an estimated four to ten times greater selling impact than radio, per person reached. Psychologists have shown that some persons learn best by hearing, some by seeing, but that all learn best by a combination of hearing and seeing.

WoLfE, op. cit. supra note 38 , at 673 . Psychological memory experiments indicate strongly that people tend to remember advertising messages presented by a combination of visual and auditory methods significantly more than those presented by either method alone. Sec, e.g., Elliott, Memory for Visual, Auditory, and Visual-Auditory Matcrial, 29 Arcurves of Psychology No. 199, at 52-54 (1936).

Being deprived of the use of television can be a serious competitive disadvantagc. This is strikingly exemplified by figures showing the marked increase in sales to the sponsor of the now defunct " $\$ 64,000$ Question" and "64,000 Challenge" shows. The 1954 net sales of Revlon, the sponsor, were $\$ 33,604,000$. Revlon began advertising on the show in the middle of 1955 . Sales for that year increased to $\$ 51,647,000$. In 1956 they increased to $\$ 85,768,000$, in 1957 to $\$ 95,175,000$, and in 1958 to $\$ 110,363,000$. Pharmaceuticals, Inc., sponsor of the tremendously popular quiz show "Twenty-one" noted a sales increase of $68.9 \%$ for "Sominex" during a 12-week period of sponsorship, and a jump in sales of $71.4 \%$ for "Geritol" during a three-week period. See Report to the President nY tHe Atromnex Generai on Deceptive Practices in Broadcasting Media 20-22 (1959).

Television clearly affords the advertiser access to the greatest number of potential consumers:

In 1961 there are 538 commercial stations, 63 educational stations beamed to 47 million television homes and 55 million sets.... The industry estimates that the average 
lessen its advantages by making tests or demonstrations impossible." The employment of a false element in a television commercial solely to compensate for technical difficulties, therefore, should be permitted ${ }^{28}$ so long as the presence

family set is turned on 5 hours and 22 minutes a day. Each day, American children under 12 spend more than 70 million hours watching television. ...

Television has been an astounding commercial success. Last year [1960] the Nation's 100 biggest advertisers spent 53 cents of every national advertising dollar on television. ... When we add it all up we find that more than $\$ 1 / 2$ billion a year is being spent on television.

Address by Newton N. Minow, Chairman, Federal Communications Commission, Dec. 22, 1961, p. 4.

Nor does it seem that the use of television by those not faced with technical problems will slow down. In 1960, for example, the investment in television by advertisers totaled $\$ 1,605,000,000$, an increase of $939 \%$ from 1950 . N.Y. Times, Jan. 24, 1962, p. 1, col. 6 .

47. See Wolfe, op. cit. supra note 38, at 663; Heprer, Effective Advertisnic 329-34, 480 (picture caption) (1941).

48. It is probable that the FTC would allow the advertiser to use props or mock-ups in his television commercials provided he discloses their existence. Even the extreme abuses of "payola" and fixed quiz shows can be corrected simply by informing the public that the disc jockey received consideration for playing particular records or that quiz contestants were given answers before the show. See F.C.C. Reports, Proposed Rules to Denz witu Fixed "Quiz" AND other Contest Prograsrs (1960), and F.C.C. Release, July 29, 1960, pp. 3-4. More analogous are decisions recognizing disclosure as a way to permit a manufacturer to describe his product in the most expeditious fashion. See, c.g., FTC v. GoodGrape Co., 45 F.2d 70, 72 (6th Cir. 1930), and FTC v. Mforrissey, 47 F.2d 101 (7th Cir. 1931), involving the incorporation of names of fruit in trade-names for soft drinks made totally of artificial flavoring and color. In each case the court required disclosure but struck: down that part of the FTC order requiring complete elimination of the descriptive words. The court was concerned not with protecting the advertiser's interest in a long-established trade name, but with giving him sufficient flexibility to describe his product:

To deny to one making such product the right to use in any way the name of the fruit which it simulates would unduly restrict the opportunity or right to describe it. Let us say that in flavor and color it resembles the orange. This might not be fully describable unless the word "orange" was employed.

47 F.2d at 103. Accord, FTC v. Hires Turner Glass Co., 81 F.2d 362 (3d Cir 1935). But see FTC v. Army and Navy Trading Co., 88 F.2d 776 (D.C. Cir. 1937) ; W.N. Hausner and Son v. FTC, 106 F.2d 596 (3d Cir. 1939); El MLoro Cigar Co. v. FTC, 107 F.2d 429 (4th Cir. 1939).

From the advertiser's viewpoint, however, the requirement of disclosure will still impose serious restrictions. Even where disclosure is permitted to legitimize an otherwise illegal advertising device, for example, the disclosure must be made sufficiently conspicuous to assure that virtually everyone will recognize it. The leading case is Parker Pen Co. v. FTC, 159 F.2d 509 (7th Cir. 1946). In a four-color magazine campaign, the Parker Pen Company ran the standard claim: "Guaranteed for Life by Parker's Blue Diamond." The slogan was printed in large type next to a $1 / 2$ inch picture of a blue diamond. Elsewhere in the layout, in smaller type and next to a smaller blue diamond cut, the qualification was printed, "Pens marked with the Blue Diamond are guaranteed for the life of the owner against everything except loss or intentional damage, subject only to a charge of $35 \%$ for postage, insurance and handling, provided complete pen is returned for service" The court affirmed the FTC's decision that the insignificant appearance of the qualification did not correct the misleading statements in the main "guarantee," although the court refused to cniforce the Commission's order completely prohibiting further use of the guarantee. In the "sandpaper case," the advertiser argued that use of the word "soak" in the audio portion sufficiently 
of such a false element does not result in the kind of consumer injury falling within the spectrum. ${ }^{49}$

qualified the visual representation that "Rapid Shave" could shave sandpaper within twenty seconds. The Commission rejected the argument, holding that one spoken word is too insignificant a qualification to communicate to most viewers that the test was not taking place precisely as depicted. 3 Trade Reg. Rep. $\llbracket 20,470$. Cf. Carter Products, Inc., 3 Trade Rea. REP. $\uparrow 15,859$ (1962), holding the word "ordinary" insufficient by itself to correct an overall false impression conveyed by a commercial. It seems, therefore, that any qualification required to permit the use of a prop or mock-up would have to appear on the television screen, if visually presented, in fairly large, visible letters for several seconds or, if orally presented, couched in a sentence or two long enough to use several seconds in order to attract everyone's attention.

This puts the advertiser using props or mock-ups to at least three disadvantages. First, one of the basic rules of radio or television advertising is to keep the number of ideas presented to a minimum, preferably one. To introduce an extraneous idea through a qualifying phrase may destroy much of the impact in a short 30-second or one minute messagc. See WoLfE, op. cit. supra note 38, at 499, 535. Second, the cost to an advertiser of reserving even 20 or 30 seconds of television time is enormous. For example, a single 20 second spot announcement between 7:59 p.m. and 11.14 p.m. on WNBC-TV, New York, costs $\$ 2,300 ; \$ 2,400$ on WCBS-TV between 8:00 p.m. and 11:00 p.m.; and $\$ 1,800$ on WABC. TV between 8:00 p.m. and 10:30 p.m. See Standard Rate amd Data Service, Sror Television Rates and Data 347-49, Feb. 15, 1962. If an advertiser has to spend part of that time to set the stage for his test or demonstration, his per-second rate can be sharply increased. Finally, an advertiser is communicating to an already skeptical audience. If he must admit that the test he is performing really is a dummy, much of the audience, concluding $a b$ initio that no authentic test is possible, will mentally dismiss his message, cven though an announcer might also explain truthfully that the test had been performed authentically off-camera.

Moreover, a constant barrage of qualifications, which quickly would be fashioned into standard, repetitious language, could become very annoying to the television viewer. Tho FCC has recognized these problems, and amended its earlier requirements that broadcasters make an appropriate announcement whenever their programs had been pre-recorded. Present rules require such an announcement only "where time is a significant factor." 47 C.F.R. $\$ \S 3.118$ (radio), 3.288 (FM), 3.653 (television). The National Association of Radio and Television Broadcasters presented the following argument, which was adopted by the FCC in moderating its policy of full disclosure:

It is urged that both the public and the broadcasting industry will be served by the elimination of announcements where the public's knowledge whether the program is recorded does not affect the value of the program or make any difference as a matter of public interest, convenience or necessity; that such announcements serve only to cause repetitious interruptions of program continuity and program inbalance; that they are both an annoyance and a distraction to the listener or viewer and a costly and unnecessary burden on broadcasting stations, and that they consume broadcast time which can be used by the station and the public to better advantage.

14 Pike \& Fischer, Radio Regulation 1541, 1544 (1956). To the same effect are the following words by John C. Doerfer, past Chairman of the FCC:

It would, in my opinion, be impractical and serve no useful purpose to require an announcement that props are being used, e.g., that the child portrayed in a charity drive is not really crippled, that the speaker is not making an extemporaneous speech but is using a teleprompter, or that the family portrayed in the commercial are parttime actors who really are not related to each other.

Address before the Television Bureau of Advertising, Inc., Nov. 20, 1959, p. 14.

49. See note 14 supra and accompanying text.

One of the most important public functions of advertising is the informative function- 
A disregard for technical difficulties evidenced in the "sandpaper" dictum would expand Section 5(a) into an area in which the false element employed in the advertisement would not cause injuries peculiar to the consumer. Use of plexiglass, for example, instead of real sandpaper, does not injure the consumer of the shaving cream so long as, accepting the FTC's own hypothetical, it has all the properties depicted in the commercial. For any possible injury that may arise out of such a substitution is an injury common to all televsion viewers in being shown one thing while being told it is another. True, such a practice may constitute a "deceptive" practice in the broadest sense, but it does not in any way injure consumers, whose specific protection was the primary concern of the act. ${ }^{50}$ In this sense, the FTC has invaded the area of general

to educate the public about the nature, quality, price and use of products available in the market.

From the point of view of the economic purist, imparting information is the only useful function of advertising. A perfect market demands perfect enlightenment of those who buy and sell. One of the many imperfections of the real world is that, absent advertising, most buyers would have to go to a great deal of trouble to discover what is offered for sale. To the extent that the blandishments of sellers inform buyers what is to be bought, and at what price, advertising undoubtedly helps to quicken the stream of commerce.

Brown, Advertising and the Public Interest: Legal Protcction of Trade Symbols, supro note 14, at 1168 (1948). But a rule prohibiting the use of props or mock-ups to correct distortions caused by the technical shortcomings of television would impede this function, for it would mean that some products never could be shown to the public, or shown very inaccurately.

Moreover, a rule banning props or mock-ups as an adjustment to inherent difficulties, ironically, will itself produce many of the evils the critics usually cite to condemn advertising. See note 14 supra. It is often suggested, for example, that advertising decreases free competition, by allowing the wealthiest corporations to dominate the market primarily because of their economic power rather than the quality of their goods. It is, however, at least as valid to speculate that advertising aids competition, through encouraging the entrance of new businesses into the market by affording them the means of publicizing their existence and announcing whatever unique contributions they might have to make. But a rule that effectively forecloses the largest advertising medium to businesses whose products require the use of substitute devices on television clearly discourages competition. This is especially true where competition exists through a "cross-elasticity of demand," as between a dessert such as ice-cream or jello, which cannot be televised, and others, such as andy or certain pastries, which face no technical problems with television.

It is also frequently argued that advertising inherently is wasteful because it increases consumer costs for items that later cannot be enjoyed. If this is true, a rule that will force certain advertisements into less effective media, or make television advertising more difficult and costly will increase consumer costs even more.

50. The FTC in the "sandpaper dictum" suggests that the mock-up deprived the consumer of getting what he bargained for. 3 TRADE REG. REP. at 20,480-81. But this is not accurate. So long as the product has the qualities depicted-i.e., ability to shave real sandpaper in twenty seconds-the consumer gets everything he expected. Elsewhere the opinion reasons that had the advertiser not used the mock-up, he would have been unable to make the claim as he did. Consequently, the Commission argued, the consumer who was swayed by the dramatization would not have been influenced to make the purchase. The use of the mock-up, it concluded, thus directly caused some consumers to spend money they might otherwise not have spent, and thereby injured competitors "whose products might have 
television viewer protection by expanding the scope of Section $5(a)$ beyond mere consumer protection. 51

The test suggested here is supported by a line of non-television cases holding that all elements of untruth need not be disclosed. In an early case, for example, involving a manufacturer of furniture who advertised his product to the trade as "mahogany" or "walnut" when in fact it was merely veneered plywood, the court reversed the FTC's disclosure order on grounds that everyone in the trade knew that the words "mahogany" and "walnut" referred to laminated wood. 52 Similarly, a court refused to prohibit an advertiser from calling his shoes "Kaffor-Kid" even though they contained no skin of young goats. The court decided the case upon evidence that the word "kid" communicated to the ordinary consumer qualities of texture and appearance, not the source of the-leather, about which he was not concerned in the slightest. The court suggested that consumers understood that ordinary "kid gloves" or "kid shoes" do not contain leathers tanned from the skins of kids. ${ }^{53}$ More recently, a court permitted unqualified use of the words "Elasti-Glass" to describe a product essentially made of plastic by noting that the word "glass" in the public mind derives from the appearance of the product, not from the manufacturing process or specific contents. ${ }^{54}$ The determinative factor in all these cases was that the consumer was not misled into expecting something different from what he actually acquired despite the false element in the advertisement.

Except for the dictum in the "sandpaper" case, the policy of both the courts and the FTC in allowing the use of what could be considered a misleading element in an advertisement to counteract technical limitations has been consistent with the test formulated here. ${ }^{55}$ In Hutchinson Chemical Corp. ${ }^{50}$ for

fared better in the market-place. ..." Id. at 20,481. The trouble with this suggestion, however, is that if indeed the mock-up produced added sales (and empirically there is no way to ascertain this), it did so only because it succeeded in its purpose, which was to demonstrate accurately a characteristic of the product.

51. Even the FCC, which is charged directly with regulating television broadcasting, seems not to consider all false elements in broadcasts so serious as to warrant their absoluto prohibition. As discussed in note 48 supra, announcements that a program is not "live" need be made only where time is somehow "significant." Otherwise, there is no injury so serious as to require disclosure.

52. Berkey \& Gay Furniture Co. v. FTC, 42 F.2d 427 (6th Cir. 1930).

53. Ohio Leather Co. v. FTC, 45 F.2d 39 (6th Cir. 1930). Cf. N. Flucgelman \& Co. v. FTC, 37 F.2d 59 (2d Cir. 1930) (use of words "Satin maid" and "Satinized" permitted with qualifying words "a cotton fabric . . . no silk" because "satin" signifies to the public not only a yarn but a method of weaving).

54. S. Buchsbaum \& Co. v. FTC, 160 F.2d 121 (7th Cir. 1947). Accord, International Parts Corp. v. FTC, 133 F.2d 883 (7th Cir. 1943) (refusing to require a manufacturer of automobile mufflers to qualify his claim that the muffers were coated with a substance designated to "prevent rust" by adding "not permanently"; consumer understanding of word "prevent" does not connote permanency).

55. In Gimbel Bros. v. FTC, 116 F.2d 578 (2d Cir. 1941), the court enforced an order requiring the distributor of a garment labeled "woolens" to disclose only that it was not $100 \%$ wool. It refused to enforce a broader decree, observing that, "To require cach constituent element to be described in the order of its predominance or in percentages would 
instance, involving the "flaming auto" commercial, the FTC explicitly recognized time limitations inherent in television broadcasting. In order to "prove" that a car wax could withstand extreme heat and cold, gasoline was poured onto a car fender to which the wax had been applied. The gasoline was then ignited and, twelve seconds later, doused with cold water. The Commission dismissed the charge that the demonstration was too short to prove what was purported. It said that if a fire lasting thirty seconds, a time period assumed sufficient to transfer requisite heat to the fender, would in fact prove the claim, the advertiser could limit the demonstration shown in the commercial to a shorter period to compensate for "time restrictions." for flexibility in the enforcement of Section 5(a) in order to achieve a desirable balance between protecting consumers and allowing advertisers considerable freedom, this former policy of the FTC stands in marked contrast to the dictum of the "sandpaper" case.

seem to require the retailer to make a laboratory test of each piece of goods put on salc." Id. at 579.

In the "Naphtha Soap" case, Procter \& Gamble Co. v. FTC, 11 F.2d 47 (Gth Cir. 1926), the court refused to enforce a Commission order enjoining use of the brand name unless the product contained more than $1 \%$ naphtha when sold to the consumer. This order failed to account for an evaporation process between manufacture and distribution "over which the respondents have no control" (id. at 48). Because it was, therefore, impossible for respondents to predict how much naphtha there would be when the product reached the consumer, the court held that the Commission's order should have been direeted to the amount of naphtha present at the manufacturing stage rather than at the sale, as the general rule required.

The FTC itself has recognized the need to move away from rules requiring full disclosure where compliance is rendered impossible by factors beyond the manufacturer's control. In its rules governing feather content of pillows, the Commission allows a manufacturer to claim his product is composed entirely of one kind of feather where as much as $15 \%$ is of another kind. 16 C.F.R. $\$ 200.3$ (1960). It is impossible to state with complete accuracy the contents of pillows without drastically overhauling industry-wide manuíacturing processes. See Northern Feather Works v. FTC, 234 F.2d 335, 337 (3d Cir. 1956).

56. 55 F.T.C. 1942 (1959).

57. Before the "sandpaper" dictum, hearing examiners used to recognize the technieal difficulties justification regularly. E.g., the Hearing Examiner in Carler Products, Inc., 3 Trade REg. REP. I 15,403 (1961), stated:

"Reasonable latitude is and should be granted to advertisers and advertising agencies in the use of 'make-up' where necessary to meet the technical requirements of photography."

Cf., informal remarks of a past FTC Chairman:

We realize that it is often difficult to impart true life quality to a product when it is photographed for television. . . . Where the use of props does not result in a material deception, the Federal Trade Commission would have no reason to complain... Obviously, we recognize that it is impossible to photograph ice cream properly under hot lights. If you have to use shaving cream to get the kind of head which is normal on a glass of beer, this probably would not represent a material deception, unless, of course, it was carried beyond a reasonable point. If a glass goblet glistens too much, we still aren't likely to be alarmed.

Ear1 W. Kintner, Advertising Age, Nov. 23, 1959. 